\title{
VALIDAÇÃo de UMA CARTILHA SOBRE A DETECÇÃO PRECOCE DO TRANSTORNO DO ESPECTRO AUTISTA
}

\section{Validation of a primer on early detection of Autism Spectrum Disorder \\ Validación de una cartilla sobre la detección precoz del trastorno del espectro autista}

\author{
Samila Sousa Vasconcelos \\ Centro Universitário Inta - UNINTA - Sobral (CE) - Brasil \\ Ilvana Lima Verde Gomes \\ Universidade Estadual do Ceará - UECE - Fortaleza (CE) - Brasil
}

Erika de Vasconcelos Barbalho

Centro Universitário Inta - UNINTA - Sobral (CE) - Brasil

Samara Sousa Vasconcelos Gouveia

Universidade Federal do Piauí - UFPI - Parnaíba (PI) - Brasil

\section{Guilherme Pertinni de Morais Gouveia}

Universidade Federal do Piauí - UFPI - Parnaíba (PI) - Brasil

\section{RESUMO}

Objetivo: Validar uma cartilha educativa destinada aos profissionais e trabalhadores da Atenção Básica que favoreça a detecção precoce da criança com autismo. Métodos: Pesquisa de desenvolvimento metodológico, com abordagem qualitativa, de validação de tecnologia. Realizou-se em Sobral, cidade do interior do Ceará, e na capital, Fortaleza, dividindo-se em três momentos: construção da cartilha educativa, validação por 13 juízes especialistas e elaboração da versão final da cartilha. A coleta de dados, que ocorreu entre julho e agosto de 2015, deu-se através de uma ficha de avaliação, em que os juízes avaliaram e fizeram correções e sugestões referentes à cartilha. Esses dados foram analisados pelo método de análise de conteúdo de Bardin. Resultados: Os juízes avaliaram os itens "conteúdo", "ilustrações", "aparência", "organização" e "motivação" da cartilha como adequados. As correções e sugestões feitas foram incluídas na versão final da cartilha. Conclusão: A cartilha educativa "Detecção precoce da criança com transtorno do espectro autista - TEA" mostrou-se um material educativo válido e confiável para ser utilizado a fim de favorecer o diagnóstico precoce do paciente com TEA.

Descritores: Transtorno Autístico; Diagnóstico Precoce; Tecnologia Educacional.

\section{ABSTRACT}

Objective: To validate a primer targeted at Primary Health Care professionals and workers to promote the early diagnosis of children with autism. Methods: This is a qualitative methodological development and technology validation research. The research took place in Sobral, a city in the countryside of Ceará, and in the capital, Fortaleza. The research was divided into three phases: construction of the primer, validation of the primer by 13 expert raters, and drafting of the final version of the primer. Data were collected in July and August 2015 through an evaluation form in which the raters evaluated and made corrections and suggestions regarding the primer. The data were analyzed using Bardin's content analysis. Results: The raters rated the items "content", "illustrations", "layout", "organization" and "motivation" of the primer as appropriate. The corrections and suggestions made by them were included in the final version of the primer. Conclusion: The "Early Detection of Children with Autism Spectrum Disorder $A S D$ " primer proved to be a valid and reliable educational material to be used to facilitate the early diagnosis of patients with ASD.

Descriptors: Autistic Disorder; Early Diagnosis; Educational Technology.

Este artigo foi selecionado, corrigido e aprovado para publicação pelo VI Seminário Internacional em Promoção da Saúde, seguindo suas normas e formatação. 


\section{RESUMEN}

Objetivo: Validar una cartilla educativa para profesionales y trabajadores de la Atención Básica que favorezca la detección precoz del niño con autismo. Métodos: Investigación de desarrollo metodológico de abordaje cualitativo, de validación de tecnología. Se realizó en Sobral, ciudad del interior de Ceará, y en la capital Fortaleza, dividiéndose en tres momentos: la construcción de la cartilla educativa, la validación de parte de 13 jueces especialistas y la elaboración de la versión final de la cartilla. La recogida de datos se dio entre julio y agosto de 2015 a través de una ficha de evaluación en la cual los jueces evaluaron e hicieron correcciones y sugerencias sobre la cartilla. Se analizaron los datos por el método de análisis de contenido de Bardin. Resultados: Los jueces apuntaron como adecuados los ítems "contenido", "ilustraciones", "apariencia", "organización" y "motivación" de la cartilla. Se incluyeron las correcciones y las sugerencias en la versión final de la cartilla. Conclusión: La cartilla educativa "Detección precoz del niño con trastorno del espectro autista - TEA" se mostró un material educativo válido y confiable para favorecer el diagnostico precoz del paciente con TEA.

Descriptores: Trastorno Autístico; Diagnóstico Precoz; Tecnología Educacional.

\section{INTRODUÇÃO}

O autismo foi descrito pela primeira vez em 1943, pelo psiquiatra Leo Kanner, relatando as principais características dos pacientes e como diferenciá-las de outras patologias ${ }^{(1)}$. Atualmente, o autismo caracteriza-se pela presença da denominada díade diagnóstica, que consiste no déficit de comunicação social somado a comportamentos e interesses restritos e repetitivos. Devido à heterogeneidade dos sintomas, o autismo passou a ser classificado, desde 2013, como transtorno do espectro autista (TEA) (2), que inclui o transtorno autista, o de Asperger, o desintegrativo da infância e o transtorno global do desenvolvimento não especificado( ${ }^{(3)}$.

As manifestações que, atualmente, são consideradas como evidentes no TEA incluem: comprometimento no desenvolvimento sociocomunicativo, repertório limitado de interesses e atividades, e presença de comportamentos estereotipados $^{(2)}$. No que se refere à caracterização da sintomatologia do TEA, observa-se um comprometimento maior em relação à dimensão de interação social, ao direcionamento espontâneo da atenção de outras pessoas e à brincadeira em grupo com pares. Outra situação descrita na literatura é a regressão da linguagem ${ }^{(4)}$.

Apesar de não existir, até o momento, uma evidência que respalde um diagnóstico de TEA no primeiro ano de vida e que se comprove estável, é crescente o volume de conhecimento sugerindo a possibilidade de identificação de risco de autismo neste período, ainda que não haja consenso sobre quais comportamentos observar. Uma pesquisa nesta área tem descoberto evidências que indicam que, em crianças brasileiras, existe um intervalo de, aproximadamente, três anos entre as primeiras manifestações de alerta identificadas pelos pais e a confirmação formal do diagnóstico. Isto demonstra a necessidade urgente de redução desse tempo pelos efeitos da intervenção precoce para o desenvolvimento da criança( ${ }^{(5)}$.

Embora exista a possibilidade, e mesmo a necessidade, de intervenção no quadro autístico antes de sua cronificação, alguns autores relatam que o diagnóstico precoce é identificado como gerador de dúvidas e insegurança, por apresentar uma sintomatologia difusa e manifestações clínicas sutis em seu estado inicial( ${ }^{(6)}$.

O processo de elaboração do diagnóstico está, intrinsecamente, relacionado com a interpretação que os pais atribuem e constroem acerca do diagnóstico da criança. Isto envolve as crenças sobre profissionais envolvidos, tanto no momento do diagnóstico como na forma como é comunicado aos pais, e nas intervenções, sejam educacionais, sejam clínicas, sejam em serviços de saúde e escolares ${ }^{(7)}$.

A educação em saúde promove a melhoria na qualidade de vida dos indivíduos, uma vez que essa prática é capaz de transformar os modos de vida das pessoas e das comunidades ${ }^{(8)}$. As práticas de educação em saúde utilizam materiais educativos que, por serem parte da cultura dos serviços de saúde pública e por sua condição material, atuam como dispositivos na mediação entre políticas e práticas de saúde, validando os discursos e procedimentos médicos-sanitários, o diagnóstico, o tratamento, a vigilância dos casos e a relação médico-paciente ${ }^{(9)}$.

O planejamento das ações destinadas à melhoria da qualidade da assistência à saúde mental da infância na Atenção Básica deve incluir mudanças na formação profissional que possibilitem otimizar sua capacidade de diagnosticar precocemente, realizar intervenções pertinentes à Atenção Básica e referenciar outros níveis de atenção(10).

Dessa forma, a pesquisa se justifica pela necessidade de oferecer aos trabalhadores e profissionais de saúde da Atenção Básica ferramentas e conhecimentos adequados sobre autismo, para que o reconheçam e identifiquem durante a visita domiciliar. Assim, espera-se que as crianças com características do espectro autista sejam encaminhadas para a Atenção Secundaria e tenham acesso à reabilitação de forma precoce. 
Portanto, este estudo visa proporcionar subsídios importantes, visto que traz mais uma abordagem de aprendizagem para trabalhadores e profissionais de saúde, o que influenciará tanto a Atenção Primária quanto a Atenção Secundária, melhorando a acessibilidade do usuário e a integralidade do sistema.

O objetivo do estudo foi validar uma cartilha educativa destinada aos profissionais e trabalhadores da Atenção Básica, que favoreça a detecção precoce da criança com autismo.

\section{MÉTODOS}

Trata-se de uma pesquisa de desenvolvimento metodológico, com abordagem qualitativa, de validação de tecnologia (cartilha). A validação é um processo em que se examina, com exatidão, determinado instrumento ou inferência realizada a partir de escores estabelecidos. É um processo contínuo de verificação e de constatação do valor de um instrumento de medida ${ }^{(11)}$.

A pesquisa foi realizada em Sobral e em Fortaleza, ambas localizadas no Ceará. Os passos do processo de validação da cartilha foram: 1) Caracterização preliminar dos participantes do estudo; 2) Processo de validação da cartilha.

Coletaram-se os dados entre julho e agosto de 2015, com participação de 13 profissionais de saúde, que constituíram os juízes da cartilha, sendo estes, pessoas com grande expertise em sua área de atuação. Para a seleção desses juízes, especialistas da área da saúde, estabeleceram-se os seguintes critérios: titulação, produção científica e tempo de atuação com a temática em discussão. Fizeram parte desse comitê os juízes cujo perfil tenha ocorrência de um desses critérios.

Os critérios de inclusão englobaram: ser profissional da saúde de nível superior, trabalhar com crianças com TEA; ter disponibilidade para participar da pesquisa. O critério de exclusão foi trabalhar menos de cinco anos na área da saúde da criança.

Os juízes foram convidados a participar da pesquisa mediante contato oral prévio e, posteriormente, receberam uma carta-convite, na qual foi explicado como eles deveriam proceder para avaliarem a cartilha. Ao aceitarem, preencheram o Termo de Consentimento Livre e Esclarecido e receberam uma cópia da cartilha com o respectivo instrumento de avaliação, a ser devolvido dentro de um prazo de dez dias.

$\mathrm{Na}$ ficha de avaliação da cartilha os juízes deviam avaliar a tecnologia educativa e registrar suas sugestões para aperfeiçoar o material. Essa ficha foi baseada em estudo prévio ${ }^{(12)}$. Por meio dessa ficha, os peritos fizeram análises e sugestões quanto à estrutura, ao conteúdo, à linguagem e a ilustrações contidas na cartilha. Eles deveriam julgar a clareza, a compreensão ou redundância e a adequação da representação comportamental dos itens.

As considerações dos juízes foram examinadas pelo método de análise de conteúdo( ${ }^{(13)}$, compreendendo as fases de pré-análise, exploração do material ou codificação, tratamento dos resultados, inferência e interpretação. A partir disso, foram realizadas a correção e a reformulação da cartilha, incorporando as sugestões feitas pelos juízes, a fim de atender às necessidades e expectativas a que se propõe.

Para manter o anonimato dos entrevistados e garantir o cumprimento dos preceitos éticos e legais, eles foram identificados por códigos (Juízes: J1, J2, J3...) sem guardar relação com a ordem das entrevistas. O risco que a pesquisa apresentou pode ter sido o de constrangimento durante a validação da cartilha, entretanto o estudo ocorreu de forma a minimizar qualquer risco.

Este estudo seguiu a Resolução 466/12 do Conselho Nacional de Saúde ${ }^{(14)}$, e recebeu aprovação do Comitê de Ética em Pesquisa da Universidade Estadual do Ceará, sob Parecer nº 923.587.

\section{RESULTADOS E DISCUSSÃO}

\section{Perfil dos juízes}

Os juízes selecionados eram profissionais da área da saúde, sendo seis fisioterapeutas, três terapeutas ocupacionais, um fonoaudiólogo, dois psicólogos e um neurologista.

O perfil dos juízes, segundo a titulação, aponta que 84,6\% têm formação lato-sensu e 15,3\%, stricto-sensu. O maior grau de titulação é doutorado, o que fortalece a possibilidade de uma avaliação apoiada numa visão teóricometodológica.

Quanto ao tempo de experiência da área da saúde da criança, o mínimo foi de cinco anos e o máximo, de 21 anos. Em relação à atuação profissional, todos os juízes estão, atualmente, trabalhando em área com crianças. 
A maior parte deles (seis juízes) trabalha com estimulação precoce; dois trabalham na docência, em disciplinas relacionadas à saúde da criança; dois trabalham com crianças institucionalizadas; dois atuam no atendimento geral às crianças em clínica particular e um atua como neuropediatra. Esses dados confirmam a experiência profissional dos juízes na área, garantindo uma avaliação da cartilha sustentada na vivência clínica.

\section{Validação da cartilha educativa}

A cartilha educativa submetida à validação junto aos peritos continha oito páginas; com dimensões de 200/140 $\mathrm{mm}$; impressa nas cores laranja, verde, branca e preta; em papel couchê brilho A4 de $180 \mathrm{~g} / \mathrm{m}^{2}$. O título escolhido para a cartilha foi "Diagnóstico precoce da criança com transtorno do espectro autista - TEA". Os desenhos e a arte da cartilha foram feitos por meio do programa de computação gráfica Corel Draw ${ }^{\circledR}$. As páginas receberam divisões por tópicos: "capa", "apresentação", "sobre o transtorno do espectro autista", "sinais e sintomas", "orientação aos pais e cuidadores", "percurso do usuário no Sistema de Saúde" e "referências".

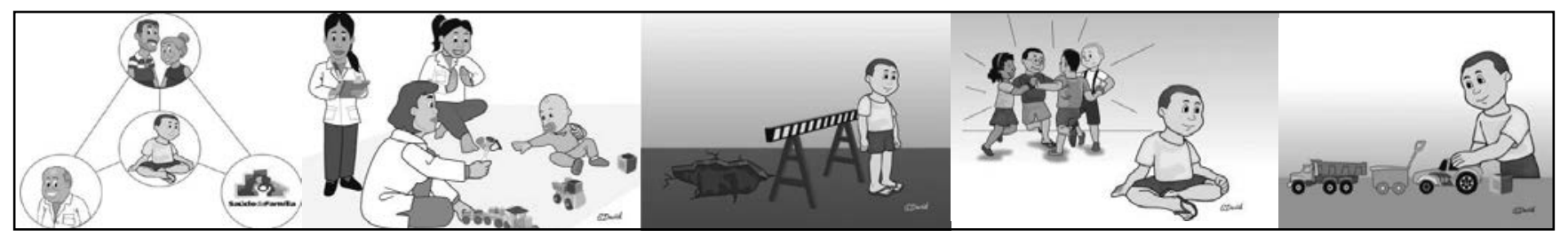

Figura 1 - Versão final de figuras contidas na cartilha após validação pelos juízes especialistas.

$\mathrm{Na}$ conjuntura da saúde, as tecnologias educativas são instrumentos importantes para a realização do trabalho educativo e do desempenho do processo de cuidar, sendo consideradas instrumentos facilitadores do diálogo, do fortalecimento da relação cliente-profissional, bem como da formação de uma consciência crítica orientada para o cuidado à saúde ${ }^{(15)}$.

A elaboração dos manuais educativos vem ocorrendo de forma a facilitar o trabalho da equipe multidisciplinar na orientação de pacientes e familiares no processo de tratamento, recuperação e autocuidado. Dispor de uma tecnologia educativa e instrutiva facilita e uniformiza as orientações a serem realizadas com vistas ao cuidado em saúde. Além disso, é também uma forma de ajudar os indivíduos no sentido de melhor entender o processo saúdedoença e de os co-responsabilizar pelo processo de recuperação(16).

As informações colhidas e analisadas proporcionaram entendimento sobre as opiniões dos juízes e os desdobramentos resultantes dos objetivos do estudo. A partir da análise das respostas dos participantes, foi possível criar categorias, cujos conteúdos manifestos e latentes apresentavam maior correlação. As categorias foram: "Características do transtorno do espectro autista"; "Composição visual e qualidade das ilustrações da cartilha"; "Adequação do material educativo à utilização na prática clínica em saúde". Após o processo de validação, foi realizada a reformulação da cartilha, com alteração e acréscimo de imagens (Figura 1).

Em relação à primeira categoria "Características do transtorno do espectro autista", os juízes fizeram observações com relação à quantidade de sinais e sintomas e à linguagem utilizada para descrevê-los.

Com relação aos sinais e sintomas relacionados ao TEA, quatro juízes sugeriram a inclusão de alguns sinais que não haviam sido abordados na cartilha. Essas considerações foram importantes, pois tornou a caracterização do TEA mais completa, aprimorando a cartilha para que ficasse mais adequada para a detecção precoce.

Na segunda categoria, chamada "Composição visual e qualidade das ilustrações da cartilha", os juízes fizeram correções e observações quanto à parte visual e ilustrativa da tecnologia. Em relação às ilustrações, três juízes consideraram a quantidade inadequada. Apesar de a tecnologia educativa ser em forma de cartilha - o que permite que o foco seja não apenas nas imagens, mas também no texto em si -, foi possível analisar a importância dos desenhos para tornar a leitura mais agradável, uma vez que torna possível exemplificar melhor algumas características. Quatro juízes sugeriram a inclusão de desenhos específicos.

Em relação à composição visual da cartilha, os juízes consideraram o material adequado e organizado. Entretanto, no processo de impressão da cartilha, utilizou-se o formato encadernado, com espiral na parte superior. E cinco juízes não consideraram isto adequado. Assim, é possível observar a importância na forma de apresentação do conteúdo, pois influenciará a adesão do público-alvo ao uso da tecnologia educativa.

Em relação ao aspecto da harmonia, apesar dos juízes terem avaliado a cartilha de forma positiva de maneira geral, na questão do equilíbrio entre a quantidade de textos e de ilustrações, dois juízes sugeriram que um dos tópicos abordados fosse dividido em duas partes. 
Em relação à terceira categoria, chamada "Adequação do material educativo à utilização na prática clínica em saúde", os juízes fizeram considerações e sugestões sobre a aplicabilidade da tecnologia educativa no contexto da prática clínica.

Em toda a ficha de avaliação, solicitava-se que os peritos avaliassem a adequação da linguagem ao público-alvo. A maioria dos juízes classificou que a linguagem era adequada e clara, entretanto houve divergência em relação à observação de dois dos juízes:

"[...] já que a cartilha é direcionada para profissionais, sugiro a utilização de linguagem mais técnica [...]." (J-1)

"[...] como garantir as informações da cartilha para o público não-alfabetizado (sic)? Uma vez que os pais e cuidadores poderão não entender as informações [...]." (J-2)

Percebe-se, por meio das duas frases acima, apesar do objetivo da cartilha ter sido explicado do TCLE, na cartaconvite e na própria cartilha em si, que alguns juízes ficaram em dúvida quanto ao público a que a cartilha se destina.

No primeiro relato, observa-se isto porque o juiz não levou em consideração os ACS, que possuem nível médio. Portanto, a linguagem não pode ser predominantemente técnica, uma vez que esses trabalhadores não possuem alguns conhecimentos específicos da saúde da criança. Na segunda frase, também se percebe o equívoco, uma vez que a cartilha não se destina a um público não alfabetizado.

Em relação à relevância do conteúdo abordado na cartilha, dois juízes sugeriram a inclusão de mais algumas temáticas importantes, tais como as áreas terapêuticas relacionadas ao processo de reabilitação da criança com TEA. Na reformulação da cartilha, esse tópico foi incluído, assim como uma ilustração que representasse o momento da reabilitação.

Quanto à adequação do material para a prática clínica, todos os juízes julgaram a cartilha como adequada e relevante, evidenciando a importância da temática para a área da saúde e a facilidade da utilização da tecnologia educativa, principalmente tendo em vista a escassez do tempo que o profissional de saúde dispõe para cada atendimento.

A avaliação por profissionais de diferentes áreas é o momento em que realmente se pode dizer que o trabalho está sendo feito em equipe, valorizando as opiniões e abordagens diversas sobre o mesmo tema. A etapa de validação é também um aprendizado, e exige que o pesquisador esteja aberto às críticas para construir algo que realmente venha a atender às expectativas e necessidades das pessoas, as quais, certamente, possuem conhecimentos e interesses diferentes dos deles ${ }^{(16)}$.

Percebe-se que o processo de validação evidencia a importância da qualificação prévia para conferir maior credibilidade ao material construído. A tecnologia educativa distribuída muitas vezes não consegue atingir o seu objetivo, trazendo resultados frustrantes, principalmente por divergir entre o que se pretende informar e o que o público-alvo considera realmente importante. A avaliação prévia, por profissionais de diferentes áreas, do conteúdo de um manual informativo e destinado à sua educação continuada, além de possibilitar que emerjam opiniões e enfoques diversos sobre o mesmo tema, dão subsídio ao conhecimento para uma prática mais segura(17).

O processo de validação é complexo e não se pode garantir que a opinião de um pequeno grupo de avaliadores possa assegurar um conjunto específico de itens como representantes legítimos do conteúdo de um instrumento ou de um processo de raciocínio ${ }^{(18)}$.

Portanto, a ideia de construir e validar um manual pelos profissionais a que é destinado, buscando experiências cotidianas da vida como fonte de conhecimento, atribui maior qualidade ao processo de comunicação na assistência em saúde e enfatiza a confiabilidade das orientações apresentadas, salientando o grau de coerência das informações em atender ao objetivo proposto(15).

\section{CONSIDERAÇÕES FINAIS}

A elaboração e construção da cartilha educativa, tendo por embasamento a revisão de literatura, são importantes quando se trabalha com temas que não fazem parte do conhecimento básico do público a que se destina, como nesta pesquisa, em que os profissionais mostraram-se com conhecimento limitado sobre a TEA.

No processo de validação da cartilha, percebeu-se a importância da participação dos juízes para adequar o conteúdo ao real contexto de trabalho desses profissionais, que contribuíram com sugestões embasadas em suas práticas profissionais e em seus conhecimentos científicos. 
Por fim, a experiência da construção de uma tecnologia educativa vivenciada com o uso da cartilha constituiu-se em um importante meio de informar, alertar, transmitir conhecimentos e promover a reflexão acerca da integralidade em saúde e do bem-estar do paciente e da família.

\section{CONFLITOS DE INTERESSE}

Este trabalho não apresenta relações que possam implicar potencial conflitos de interesse.

\section{REFERÊNCIAS}

1. Kanner L. Autistic disturbances of affective contact. Nerv Child. 1943;2:217-50.

2. American Psychiatric Association. DSM-V-TR. Diagnostic and Statistical Manual of Mental Disorders. American Psychiatric Publising. 5a ed. Washington: APA; 2013.

3. Zanon RB, Backes B, Bosa CA. Identificação dos Primeiros sintomas do autismo pelos pais. Psicol Teor Pesqui. 2014;30(1):25-33.

4. Backes $\mathrm{B}$, Zanon RB, Bosa CA. Características sintomatológicas de crianças com autismo e regressão da linguagem oral. Psicol Teor Pesqui. 2017; 33:1-10.

5. Zanon RB, Backes B, Bosa CA. Diagnóstico do autismo: relação entre fatores contextuais, familiares e da criança. Psicol Teor Prat. 2017;19(1):152-63.

6. Seize MM, Borsa JC. Instrumentos para rastreamento de sinais precoces do autismo: revisão sistemática. Psico USF. 2017;22(1):161-76.

7. Semensato MR, Bosa CA. Relatos de pais de crianças com autismo sobre a rede de apoio formal: aspectos da elaboração parental do diagnóstico. Rev Educ Espec. 2013;26(47):651-64.

8. Mallmann DG, Galindo NM Neto, Sousa JC, Vasconcelos EMR. Educação em saúde como principal alternativa para promover a saúde do idoso. Ciênc Saúde Colet. 2015;20(6):1763-72.

9. Massara CL, Murta FLG, Enk MJ, Araujo AD, Modena CM, Carvalho OS. Caracterização de materiais educativos impressos sobre esquistossomose, utilizados para educação em saúde em áreas endêmicas no Brasil. Epidemiol Serv Saúde. 2016; 25(3):575-84.

10. Munari DB, Melo TS, Oliveira MB, Barbosa CC, Queiroz ACCM, Araújo BFM. Capacitação de agentes comunitários de saúde para o cuidado em saúde mental na atenção básica: potencializando pessoas para cuidar de pessoas. Tempus. 2010;4(1):135-45.

11. Reberte LM, Hoga LAK, Gomes ALZ. O processo de construção de material educativo para a promoção da saúde da gestante. Rev. Latinoam. Enferm. 2012;20(1):101-8.

12. Reberte LM. Celebrando a vida: construção de uma cartilha para promoção da saúde da gestante [dissertação] [Internet]. São Paulo: Escola de Enfermagem da Universidade de São Paulo; 2008 [acesso em 2014 Out 15]. Disponível em: http://www.teses.usp.br/teses/disponiveis/7/7132/tde-05052009-112542/pt-br.php

13. Bardin L. Análise de conteúdo. São Paulo: Edições 70; 2015.

14. Conselho Nacional de Saúde (BR). Resolução 466, de 12 de Dezembro de 2012. Dispõe sobre as diretrizes e normas regulamentadoras de pesquisas envolvendo seres humanos. Diário Oficial União; 13 jun. 2013. Seção 1.

15. Albuquerque AFLL, Pinheiro AKB, Linhares FMP, Guedes TG. Tecnologia para o autocuidado da saúde sexual e reprodutiva de mulheres estomizadas. Rev Bras. Enferm. 2016;69(6):1164-71.

16. Echer IC. Elaboração de manuais de orientação para o cuidado em saúde. Rev Latinoam Enferm. 2005;13(5): 754-7.

17. Medeiros RKS, Ferreira MA Jr, Pinto DPSR, Vitor AF, Santos VEP, Barichello E. Modelo de validação de conteúdo de Pasquali nas pesquisas em enfermagem. Referência. 2015;IV(4):127-35. 
18. Lopes MVO, Silva VM, Araujo TL. Validation of nursing diagnosis: challenges and alternatives. Rev Bras Enferm. 2013;66(5):649-55.

\section{Endereço para correspondência:}

Samila Sousa Vasconcelos

Centro Universitário Inta - UNINTA

Centro de Carreiras da Saúde - Curso de Fisioterapia

Rua Coronel Antonio Rodrigues Magalhães, 359/ Prédio de Carreiras da Saúde

Bairro: Dom Expedito Lopes

CEP: 62050-100 - Sobral - CE - Brasil

E-mail: samilasousa@hotmail.com 